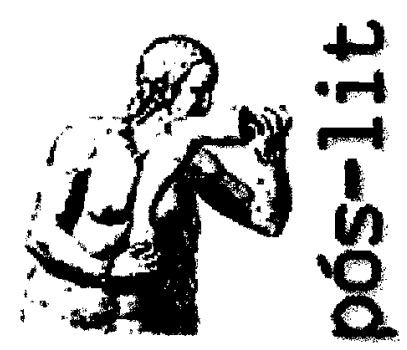

Programa de Pós-Graduação em

Letras: Estudos Literários da Faculdade de Letras da UFMG

Artigo disponível em

http://www.letras.ufmg.br/poslit

\section{A ARQUITETURA DO TEXTO BENJAMINIANO}

Rachel Esteves Lima $U F M G$

RÉSUMÉ

Cet essai a pour but l'analyse du processus d'élaboration textuel utilisé par Walter Benjamin dans les oeuvres Origem do Drama Barroco Alemão et Rua de Mão Unica, notamment en ce qui concerne le paratexte les épigraphes, les citations et la dédicace. 
Na tentativa de traçar um perfil de Walter Benjamin, a filósofa Hannah Arendt depara-se com a dificuldade de classificação para aquele que tinha como objetivo maior ser considerado o primeiro crítico literário alemão. Segundo ela, "o problema com tudo o que escreveu Benjamin é que sempre demonstrava ser sui generis"' . Realmente, torna-se difícil definir um escritor tão multifacetado: filósofo, crítico literário, memorialista, historiador, ensaísta - todos esses rótulos lhe cabem, mas o que sobressai em sua obra é o fato de que perseguindo o objetivo de recriar a crítica literária como gênero, acaba produzindo textos que se colocam entre a teoria e a arte, entre a crítica e a literatura. Isso porque, segundo a autora, acima de tudo, o que lhe determinava a direção era o seu modo de "pensar poeticamente".

Para Benjamin, caberia à crítica literária muito mais o papel de suplementar a obra literária do que o de propriamente julgá-la, proposta que, evidentemente, não condizia com a posição em que os intelectuais se colocavam, tradicionalmente. Partindo das considerações platônicas sobre a questão do conhecimento do real, Benjamin, ao contrário de Eros, não se coloca como um perseguidor da beleza, identificada no esquema platônico com a verdade, mas como um amante que percebe que jamais conseguirá atingi-la em seu cerne, mas apenas fazê-la se manifestar num processo de fulguração. Pois "a verdade não é desnudamento, que aniquila o segredo, mas revelação, que lhe faz justiça"2. Essa relação amorosa do crítico com os objetos de estudo se manifesta na originalidade da forma com que reinterpreta obras que mantêm em comum um lado gauche, uma marginalidade em relação ao pensamento oficial. Através da obra de Benjamin, esses textos são retomados, reatualizados, não apenas pela nova interpretação do seu conteúdo temático, mas também pela adesão do texto interpretaçáo do seu conto literário em questão. $O$ trabalho benjaminiano constitui-se, então, como a redescoberta de uma ruína, que assume o caráter de runa, marca de um tempo e um sonho do passado, que agora ressurge através de um novo olhar que é lançado à obra literária, na tentativa de fazer com que atinja "o ponto mais alto de sua intensidade luminosa"3.

É esse o sentido que a obra Origem do drama barroco alemão assume. Nela, não é apenas o equívoco da crítica especializada em considerar os dramas do período barroco como tragédias que é discutido, mas toda uma postura adotada na análise dos textos literários. Através de um texto denso

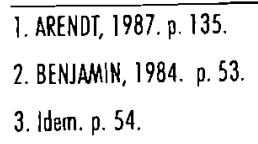

e completamente assistemático para os padrōes vigentes à época, Benjamin vai contrapor-se aos métodos indutivos e dedutivos que, baseando-se em categorias genéricas ou na historiografia periodizante e até mesmo num psicologismo estéril, faziam subsumir as diferenças, caindo num universalismo vazio ou em conceitos que não levam em conta o particular.

O Barroco impõe-se como objeto de estudo por manter relações analógicas com o contexto em que o crítico produzia sua obra, relações que se refletem na arte expressionista. Ambos os estilos são fruto de um período de decadência e trazer à luz os elementos estruturais da sensibilidade barroca pode fazer com que se compreenda um pouco mais o momento histórico que lhe era contemporâneo. Tenta-se acordar os mortos para que os vivos também despertem.

Rua de mão única ${ }^{4}$, por sua vez, apresenta-nos um outro nível de desdobramento das considerações críticas que já estão embrionariamente contidas em Origem do drama barroco alemão. Se, nessa obra, trata-se teoricamente do estudo de uma produção literária específica, o drama barroco, Rua de mão única constitui-se num texto completamente fragmentário, que não pode ser classificado segundo os padrões genéricos tradicionais, aproximando-se da técnica de montagem surrealista, pois nele são justapostos fragmentos sobre assuntos distintos que vão desde a crítica literária até o aparentemente insignificante provérbio utilizado na linguagem cotidiana. A obra significa uma completa adequação do conteúdo à forma, que atinge uma dimensão artística raramente encontrada em textos críticos. E é no entrecruzamento dessas duas dimensões de leitura que tem de ser considerada.

\section{ORIGEM DO DRAMA BARROCO ALEMÃO:}

\section{FRAGMENTOS DIALÓGICOS}

Nesse trabalho, Benjamin estabelece uma relação dialética entre universal e particular, traduzida na reflexão sobre as idéias e os fenômenos. Segundo ele, caberia à filosofia a representação das idéias, o que seria possível através da verificação dos elementos extremos que se agrupam ao redor delas, os fenômenos. A mediação entre os fenômenos e as idéias se daria através dos conceitos. Transposta essa teorização para o terreno da 
estética, os gêneros literários assumiriam o caráter de idéias e as obras literárias corresponderiam aos fenômenos. Considerando os dramas barrocos em sua particularidade, Benjamin procede ao desmembramento dos elementos que os constituem, em polarizações que, ordenadas objetivamente, vão configurar o barroco como idéia, sem que sejam abolidas as diferenças entre as obras.

Para o autor, a representaçāo das idéias por parte da filosofia só se faz possivel se for abandonada a dimensão didática do sistema, que a compreende como "guia para o conhecimento". A verdade não pode ser confundida com o "real", podendo apenas ser representada pelo filósofo: "A verdade, presente no bailado das idéias representadas, esquiva-se a qualquer tipo de projeção no reino do saber. O saber é posse"s. Em Benjamin, a filosofia enquanto representação da verdade pode ser exercida através do recurso à teologia — dai a importância da utilização dos conceitos da doutrina e do ensaio esotérico, formas que, segundo ele, "impôs-se em todas as épocas que tiveram consciência do Ser indefinível da verdade"'. O tratado é visto, então, como a forma mais adequada a essa descrição, pelo seu caráter anti-didático e pela alusão aos objetos da detalhes microscópicos. O texto se compõe como um mosaico em que elementos aparentemente contraditórios acabam entrando numa relação completamente nova.

Sérgio Paulo Rouanet define como paradigma metodológico em Benjamin a leitura monadológica do particular? ${ }^{7}$. O fragmento traz em si uma visão do todo e é esse o sentido da dialética proposta em Origem do drama barroco alemão. Dessa forma, o texto é dividido em enormes parágrafos, que se assemelham a blocos, cujos subtítulos não intercalam os vários segmentos. Aparecem apenas no índice e no alto da página, como a propor uma leitura também descontínua, determinada pela intenção do leitor, que pode gerar um novo texto, um novo mosaico.

As frases são também apresentadas como fragmentos. Assumem uma extrema concisão, interrompendo-se bruscamente para, noutro lugar, serem retomadas com fôlego também curto. Susan Sontag define o estilo benjaminiano de composição, geralmente visto como aforístico, como "barroco de estrutura fixa", ressaltando a semelhança dessas frases, em que as imagens se condensam de forma extremada, como um quadro barroco, repleto de movimento ${ }^{8}$. Benjamin assinala que o tratado se definiria como uma forma de prosa, comparável à linguagem oral, da qual se aproxima pelo uso de recursos que lhe conferem o tom e a gestualidade propícias ao diálogo que incite o leitor à reflexão. Para isso, "na escrita é preciso, com cada sentença, parar e recomeçar", pois, "quanto maior o objeto, mais distanciada deve ser a reflexão"'.

O caráter dialógico é uma constante no texto que, como o drama barroco, articula-se em termos alegóricos. A própria etimologia da palavra "alegoria" já conduz a uma duplicidade de sentidos, pois significa dizer uma coisa para significar outra. Para que se possa atingir esse outro nível de significação, a alegoria vê a morte não apenas como seu conteúdo, mas principalmente como seu elemento estruturador. $O$ alegorista, associado à figura do melancólico, é aquele que tem de matar o objeto, arrancá-lo de seu contexto para que ele possa renascer em outro universo relacional. A alegoria é composta de ruínas e fragmentos, estilhaços textuais que, entrecruzados, promovem a comunicação entre si, entre passado, presente e futuro, e entre leitor e produtor do texto. A prática da citação é inerente ao método alegórico, que pretende obter a perpetuação do significado em sua abertura plena. Benjamin, mais que ninguém, utiliza a citação como princípio estruturador do seu texto, sendo que A Origem do drama barroco alemão apresenta mais de quinhentas citaçōes, que podem ser percebidas como uma ironia dirigida à pretensa erudição dos estudiosos da literatura, mas também como uma reatualização dos textos citados na história e como um diálogo entre posições contraditórias.

Exemplar, nesse sentido, é o uso da epígrafe, a "citação por excelência"10, como um interlocutor presente entre cada parte em que se subdivide o texto, assumindo um sentido flutuante, pois poderia ser considerada, de acordo com Genette, como comentário do texto que segue, como caução deste texto, como simples demonstração de um saber acumulado e até mesmo como o próprio título da parte que introduz, uma vez que está no lugar tradicionalmente reservado a ele. Ressalte-se, ainda, que a epígrafe presente na introdução que trata de questóes teóricas referentes à crítica do conhecimento é a única em que é citado um texto crítico, curiosamente um fragmento de Goethe, a quem Benjamin admirava, mas de quem vai discordar quanto à supervalorização do símbolo

8. SONIAG, 1986. p. 100.
9. BENJAMIN, 1984. p. 51.
10. COMPAGNON, 1979.


em detrimento da alegoria. Se na epígrafe, de acordo com as funções listadas por Genette, a dialética entre universal e particular é retratada e endossada por Benjamin, ironicamente, mais adiante, a mediação proposta por Goethe entre os dois níveis já não encontra amparo na concepção benjaminiana.

As demais epígrafes da obra analisada assumem no texto o papel de mônadas, segundo a configuração estabelecida por Benjamin: são fragmentos que contêm em si a totalidade, uma condensação do que será dito adiante. Ao mesmo tempo, são como trampolins, como passagens que ligam uma parte a outra, para usar uma imagem cara ao autor: Entre elas, citações de dramaturgos do barroco alemão abrem a cortina para a cena que vai começar.

\section{RUA DE MÃO ÚNICA: BRIC-À-BRAC}

O caráter assistemático de a Origem do drama barroco alemão não impede, entretanto, que uma certa ordenação das idéias se fizesse presente. Afinal, tratava-se de uma tese com a qual o autor pretendia ingressar na Universidade de Frankfurt. Dessa forma, a divisão em três partes é fixa nos dois capítulos, que são antecedidos por uma espécie de prefácio onde lança os pressupostos de sua metodologia. Rua de mão única, publicado quando o autor já havia desenvolvido ainda mais o seu estilo, sem se preocupar com o academicismo dominante nos textos da época, apresenta uma total assistematicidade, já de início notada pela falta de definição genérica.

O texto é uma grande miscelânea, onde o autor se propõe a apresentar a "atualidade como avesso da História"ll. A fragmentação é uma constante - compõe-se de notas de viagem, aforismos, descrição de sonhos, comentários sobre literatura, crítica, filosofia, comportamentos, apologias, apresentação de quadros infantis, citações de poemas, epígrafes deslocadas, etc.. Nesse denso almanaque, vigora o propósito de desestruturar os hábitos de leitura então vigentes, a exposição de aspectos da vida cotidiana de acordo com os padrões da cultura de massas, numa adequação da escrita à forma predominante na modernidade.

Segundo Susan Sontag, "os temas recorrentes de Benjamin são, tipicamente, meios de espacialização do mundo"'2. Há nele uma relação direta entre a memória e a percepção topográfica dos acontecimentos e dos textos assimilados. A cidade torna-se, assim, o campo privilegiado para suas reflexões, onde, como oflâneur que tão bem descreveu, faz perambular o seu pensamento, em associações inusitadas e surpreendentes. Se Willi Bole está correto em considerar na obra de Benjamin a cidade como um texto $^{13}$, o inverso também se torna verdadeiro, uma vez que seu texto também se estrutura como uma cidade, vista superficialmente, mas também em conexão com sua vida interior, numa construção verbal que tenta fazer surgir o que se esconde atrás da fachada. Mais uma vez a forma do tratado se coloca, explicitamente, no tópico "Arquitetura Interna", onde metalingüisticamente descreve o método de composição do texto como uma construção árabe, em que as articulaçōes só começam no seu interior, uma vez que as fachadas (os subtítulos, se assim podemos considerar as conexões entre os tópicos) são apenas ornamentos que, como num labirinto, vão fazer com que o leitor, perdido diante de sua diversidade e abundância, se veja obrigado a imergir no texto, em busca de um significado. Nesse labirinto, em que cada fragmento se torna uma porta de entrada para o texto, reina o prazer de se perder, a sensação de desorientação: a procura de um ponto de referência produz um efeito de deslumbramento único, pela possibilidade de obtenção de uma visão panorâmica; efeito transitório, que passa quando se começa a leitura, assim como a fachada desaparece quando se entra na construção, fazendo com que a imagem que se formou de início em nossa percepção nunca mais seja reencontrada.

Benjamin lembra que oflâneur vê na cidade a realização do antigo sonho humano do labirinto ${ }^{14}$. O flâneur mantém com a cidade uma relação amorosa, pois só ele lhe percebe os detalhes, lhe confere um significado que vai além da aparência, em devaneios que fazem com que a cidade seja vista como um prolongamento de seu próprio corpo, sendo que conhecer a cidade acaba significando conhecer a si próprio, pois as imagens que se formam no inconsciente são relacionadas com a experiência vivida em cada momento de contemplação. Olgária Matos vê no gesto benjaminiano de rememoração e da constituição da topografia da cidade uma identificação com a criança que busca uma explicação para o não cumprimento da promessa de um paraíso perdido:

\section{SONTAG, Op. cit. p. 90.}

13. BOLLE, 1984.

14. BENJAMIN, 1989. 0 flâneư, p. 203. 
À cidade do absolutamente visível - racionalista e abstrata - se contrapõe a cidade infantil e alegórica, a cidade labiríntica com a qua a crianca estabelece pactos secretos. E a cidade com suas múltiplas possibilidades: intersecções, passagens, desvios, becos-sem-saída, ruas-de-mão-única que constituem os espaços de autonomia. Há uma linguagem secreta habitando esses lugares fugidios por onde passam o flâneur e a criança. Nessa 'paisagem metafísica', em cujos espaços de sonho as pessoas têm uma existência 'breve e sombria', a criançaalegorista irá mapear sua topografia, para compreender como foi perdida ${ }^{15}$.

A apresentação de atualidades efetuada por Benjamin em Rua de mão única sofre a influência de dois lados aparentemente contraditórios, mas que na obra desse autor sempre se colocam numa perspectiva dialética, em que marxismo e messianismo judaico se completam. Se o conteúdo indica a predominância da crítica à modernidade e à alienação do sujeito diante da ascensão burguesa, a forma em que este é apresentada mantém o predomínio das imagens, que assumem importância fundamental em sua teoria da linguagem, de base teológica.

Ernst Bloch afirma que a obra analisada se constitui como um "bazar filosófico", em cuja topografia são tratados aspectos aparentemente superficiais da metrópole: placas e cartazes publicitários, anúncios de jornais, lojas estrangeiras de comércio, etc., convergindo para uma abordagem sociológica que expõe as dificuldades por que passavam a classe média e o operariado no pós-guerra ${ }^{16}$. Pierre Missac, endossando essa visão, credita à orientação de Benjamin em direção a uma linha sociológica e política nessa obra o fato de ela ser dedicada a Asja Lacis, amante do autor, que o induzira ainda mais a adotar uma postura marxista ${ }^{17}$ - "Esta rua chama-se Asja Lacis, em homenagem àquela que, na qualidade de engenheiro, a rasgou dentro do autor". A perspectiva utópica benjaminiana, se é que podemos assim dizer, se faz presente num sentido que pode ser conferido ao título: Einbahnstrasse, rua de mão única, ou contramão, uma direção oposta à tomada pela História, a "contrapelo"18: "A Paris e a Berlim benjaminianas são os momentos de recuperação de um passado não para o repetir, mas no sentido de improvisar o futuro, realizando as promessas da humanidade decepcionada"19

15. MATOS, 1989. p. 80.

16. BLOCH, Enst. Apud MATOS, op. cit. p.82.

17. MISSAC, 1988. p. 84

18. BENJAMIN, 1985. Sobre o conceito de história, p. 223

19. MATOS, op. cit. p. 82
A crise econômica refletida no texto benjaminiano impõe ao crítico literário, ao intelectual em geral, uma situação de penúria e indigência. Proletarizado e ameaçado pelos preconceitos emergentes em situaçōes de decadência, o crítico não pode furtar-se a tomar posição e deve fazer com que a obra de arte se transforme em "arma branca na batalha dos espíritos"20. A crítica passa a ser vista como uma questão moral, em que a objetividade deve ceder lugar ao espírito de partido. Como arma, a crítica deve fazer com que sua produção se aproxime da contemporaneidade, tanto temática quanto formalmente. É esse o procedimento básico em $R u a$ de mão única, que denuncia, através de uma linguagem em que pontua a ironia, o pedantismo dos críticos tradicionais que, sob a aparência de objetividade científica, estabelecem parâmetros obsoletos na construção de "catataus" que apresentam apenas uma exposição palavrosa que já não corresponde à realidade.

Se, por um lado, o texto expõe a flânerie do pensamento benjaminiano, na descrição de sensações vividas no vagar pela cidade, por outro, percebe-se que as fachadas, os subtítulos, como vitrines, denunciam a situação do crítico como um comerciante que tem que vender o seu produto, mesmo lúcido e incitante à reflexão, sob a aparência de uma mercadoria qualquer. O crítico é aquele que tem de vender gato por lebre, passar o seu ponto de vista através da ilusória linguagem da publicidade.

Nesse ponto, a estruturação, a arquitetura textual da obra apresenta paralelos com o teatro de Bertold Brecht, o amigo cuja obra se torna paradigmática na concepção benjaminiana de arte. $O$ teatro brechtiano acompanha a evolução dos meios de comunicação, assimilando técnicas específicas do rádio, do cinema e da publicidade, em geral. A gestualidade buscada em suas produções pressupõe uma interrupção brusca das cenas, que devem condensar em si um valor de fragmento a ser visualizado independentemente do todo. A cenografia segue o princípio do teatro literalizado, com a predominância de cartazes, imagens visuais que proporcionam um diálogo com a atualidade e com as instituiçóes de atividade intelectual. Trazendo para o palco elementos determinantes da vida cotidiana massificada, Brecht "oferece o grande espetáculo das contradições da nossa ordem social"2l. Dessa forma, desloca o sentido da recepção do que é tipicamente teatral, impondo a realidade como uma farsa, em que autenticidade e identidade são apenas lugares comuns.

20. BENAAMN, 1987. P. 33.

21. BENJAMIN, 1985. p. 85 
Já no ponto de partida de Rua de mão única, no tópico "Posto de Gasolina", Benjamin ressalta a impossibilidade de a obra literária ou crítica manter o "pretensioso gesto universal do livro", devendo se inscrever em formas mais modestas, de acordo com a sensibilidade moderna, em uma "linguagem de prontidão" própria dos cartazes publicitários, das folhas soltas, artigos de jornal, enfim, das formas fragmentárias que acompanham a atrofia da experiência na sociedade de massas. ${ }^{22}$

Com Brecht, Benjamin aprendeu a utilizar o "pensamento cru", que deveria ser percebido como uma manifestação da realidade contida nos provérbios e expressóes idiomáticas do cotidiano. O provérbio é concebido por Benjamin como "ruínas de antigas narrativas, nas quais a moral da história abraça um acontecimento como a hera abraça um muro". ${ }^{23}$ A arte da narrativa, segundo ele, só é possível numa sociedade comunitária, onde o trabalho assume um caráter artesanal e as palavras mantêm uma relação direta com a realidade. A partir do desenvolvimento capitalista dos meios de produção torna-se impossível transmitir uma experiência vivida, já que ele pressupõe a descontinuidade e a fragmentação que vão caracterizar a busca pelo sentido da vida no romance e a informação. Nesse contexto, a dissociação entre vida e palavra é irremediável, sendo que a linguagem apenas recupera restos, ruínas de uma época em que a sabedoria era um dom cuja transmissibilidade entre gerações estava garantida. Os provérbios, próximos à fala cotidiana, pertencentes ao registro oral de comunicação, assumem, então, o papel de tentar resgatar o sonho humano da verdadeira comunicação. Portanto, o uso de provérbios e expressões idiomáticas em Rua de mão única, num contexto completamente diferente das sociedades pré-capitalistas, opera um deslocamento que propicia o desvendamento dos preconceitos, do lugar-comum que se tornaram, do caráter dialógico que passam a assumir na vida cotidiana, como uma forma de mascaramento da realidade, uma imagem sem fundo, enfim.

Esse gosto pelo deslocamento e a desarticulação dos textos no contexto é uma marca registrada no pensamento benjaminiano. O prazer pelo minúsculo, a imersão no detalhe aparentemente insignificante e o uso abundante de fragmentos constituem a base de toda sua metodologia. $\mathrm{Na}$ verdade, Benjamin coloca-se como um colecionador, cuja obsessão pelo registro de comentários, frases, provérbios, fragmentos textuais, define o trabalho da citação. Como a criança que tem presença assegurada em

22. BENJAMIN, 19B7. p. 11.

23. BENJAMIN, 1985. 0 narrador: consideraşöes sobre a obra de Nicolei Leskov, p. 221 grande parte de sua produção, e especialmente em Rua de mão única, os materiais aparentemente inúteis que são recolhidos no dia-a-dia, quando justapostos, ou sobrepostos, acabam se transformando em um novo feixe de relações, em que os restos obtêm uma nova significação. Como afirma o autor, "em produtos residuais (as crianças) reconhecem o rosto que o mundo das coisas volta exatamente para elas, e para elas unicamente". ${ }^{24}$

$\mathrm{Na}$ prática benjaminiana da coleção, que se traduz no uso insistente de citações, o objetivo de resgatar o passado para o presente, função do historiador dialético, se torna possível, uma vez que, através da rememoração, os textos são reatualizados, em um relacionamento de mosaicos que conduz a uma nova interpretação de seu significado, a uma rearticulação que produz o diálogo entre várias épocas, salvando-os do senso comum em que se transformaram e resgatando o sonho que em cada época foi possível ser sonhado: "Citações em meu trabalho são como salteadores no caminho, que irrompem armados e roubam ao passeante a convicção". ${ }^{25}$

Buscar o sentido original da palavra: talvez seja esse o objetivo principal de Benjamin em seus trabalhos. De acordo com sua filosofia da linguagem, a busca das correspondências, das analogias entre épocas, textos e palavras distintas aponta para o sentido primordial que obtiveram quando de sua nomeação. Citar uma palavra é, então, nomeá-la, pois sua rearticulação em contexto diferente conduziria ao sentido original que, entretanto, só pode ser visto como relação: como abertura ao novo, mas não como totalidade.

A arqueologia do verbo empreendida por Benjamin em seu modo de articular as palavras e citações, a proposição de imagens que conduzem a vários significados que se corporificam na leitura incitam o leitor a também construir o seu próprio mosaico com os fragmentos expostos. Torna-se significativa também a descrição dos sonhos do autor, como uma forma de rememoração, de reencontro com o olhar infantil diante das coisas, na busca do que ficou apenas no domínio da memória involuntária, no fundo do inconsciente, que se traduz em imagens que atingem a dimensão de profundidade: subterrâneos, subsolo, escavação, etc.. Em "Lembranças de viagem", o autor explicita o seu modo de conceber as associaçōes que conduzem à produçāo de imagens. $\mathrm{E}$ isso se dá também através do sonho, como uma viagem que reestrutura as lembranças para

24. BENJAMIN, 1987. p. 19.

25. Idem. p. 61 . 
compor um novo painel visual, em forma de constelação:

Em sonho saí de uma casa e olhei o céu noturno. Um selvagem resplandecer emanava dele. Pois, estrelado como ele estava, as imagens segundo as quais se formam conjunçōes de estrelas, estavam ali, em sensível presença. ${ }^{2 !}$

Rua de mão única deve ser visto como um puzzle cujas peças embaralhadas fornecem condições para a formação de inúmeras paisagens por parte do leitor, paisagens que certamente vão lhe convidar a uma imersão no particular para que lhe sejam abertas as portas da percepção.

\section{REFERÊNCIAS BIBLIOGRÁFRICAS}

ARENDT, Honnoh. Homens em tempos sombrios. São Paulo: Componhio das Letros, 1987. BENJAWIN, Wolter. Origem do dromo bur

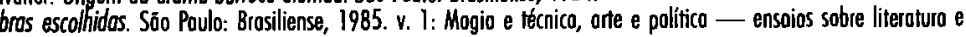

Obros escolhidos. Sốo Paulo: Brosiliense, 1987. v. 2: Rua de mõo único.

Obros escolhidos. São Paulo: Brasiliense, 1989. v. 3: Charles Baudeloire — um lírico no oune do copitolismo. B0LLE, Willi. Fisiognomia do metrópole maderno. Fotho de São Poulo. Sõo Poulo, 9 dez. 1984. Folhetim. (O)

Rio de Joneiro: Compus, 1988.

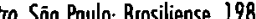

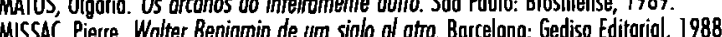

SONTAG, Susan Sob o signo de Satumo. Porto Alepre: 18 PM, 1986.

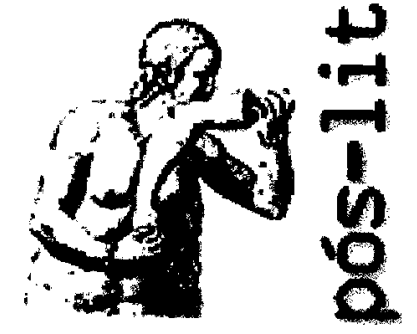

Programa de Pós-Graduação em Letras: Estudos Literários da Faculdade de Letras da UFMG

Artigo disponível em http://www.letras.ufmg.br/poslit 